\title{
AVALIAÇÃO DA USABILIDADE DA PLATAFORMA LATTES: COMPREENDENDO OS NÍVEIS DE DESEMPENHO E SATISFAÇÃO DO USUÁRIO
}

\section{USABILITY EVALUATION OF LATTES PLATFORM: UNDERSTANDING THE USER PERFORMANCE AND SATISFACTION LEVELS}

\author{
Christofer Ramos ${ }^{1}$, Esp. \\ Rosielli De Sá E Silva², Esp. \\ Marcelo Gitirana Gomes Ferreira ${ }^{3}$, Dr. \\ Milton José Cinelli ${ }^{4}$, D.Sc. \\ Monique Vandresen ${ }^{5}$, Dra.
}

(1) UDESC - Universidade do Estado de Santa Catarina e-mail: ch.rds@live.co.uk

(2) UDESC - Universidade do Estado de Santa Catarina e-mail: rosiellisa@gmail.com

(3) UDESC - Universidade do Estado de Santa Catarina e-mail: marcelo.gitirana@gmail.com

(3) UDESC - Universidade do Estado de Santa Catarina e-mail: milton.cinelli@udesc.br

(3) UDESC - Universidade do Estado de Santa Catarina e-mail: mvandresen@gmail.com

Usabilidade, Plataforma Lattes, Experiência de Usuário.

O estudo objetivou avaliar a usabilidade da plataforma Lattes nos aspectos de desempenho e satisfação do usuário. Para isso, utilizou-se como métricas de usabilidade o sucesso, o tempo e a satisfação do usuário na realização das tarefas. Os resultados sugerem inconsistências no sistema que repercutem na experiência do usuário.

\section{Usability, Lattes platform, User Experience.}

The study aimed at evaluating the usability of Lattes platform in what concerns to the aspects of user performance and satisfaction. To that intention, the usability metrics user's success, time and satisfaction were used during task performances. The outcomes suggest system inconsistencies which affect user experience. 


\section{$16^{\circ}$ \\ ERGODESIGN USIHC CINAHPA}

$16^{\circ}$ Ergodesign - Congresso Internacional de Ergonomia e Usabilidade de Interfaces Humano Tecnológica: Produto, Informações Ambientes Construídos e Transporte

$16^{\circ}$ USIHC - Congresso Internacional de Ergonomia e Usabilidade de Interfaces Humano Computador

CINAHPA | 2017 - Congresso Internacional de Ambientes Hipermídia para Aprendizagem.

\section{Introdução}

A Plataforma Lattes é o resultado da iniciativa do Conselho Nacional de Desenvolvimento Científico e Tecnológico $(\mathrm{CNPq})$, para integrar em um ambiente disponível online as principais agências de fomento federais e estaduais a uma base de dados composta por Currículos, Grupos de Pesquisa e Instituições em um único Sistema de Informações. Sua base de dados é ferramenta estratégica para direcionamentos em planejamento, gestão e operacionalização do $\mathrm{CNPq}$, além de disponibilizar o acesso a profissionais e projetos para pesquisas do Ministério da Ciência e Tecnologia e outros órgãos estatais (AMORIM, 2003; BRITO, QUONAM \& MENA-CHALCO, 2016).

O Currículo Lattes, um dos recursos desta plataforma, tornou-se referência acadêmica e científica nacional e representa um histórico das atividades e produções de pesquisadores no Brasil. Assim, as informações contidas em um Currículo Lattes são utilizadas como critérios avaliativos para instituições como a CAPES (Coordenação de Aperfeiçoamento de Pessoal de Nível Superior) e outros órgãos de pesquisa; seleção de estudantes e candidatos a bolsas e auxílios; avaliação de cursos de Pós-Graduação; seleção de corpo docente em processos seletivos; acompanhamento da produção científica e tecnológica nacional; entre outras atribuições do gênero (AMORIM, 2003; BRITO, QUONAM \& MENA- CHALCO, 2016).

Ocorre que, mesmo diante de sua relevância, ao que parece, a interface dessa plataforma apresenta problemas de usabilidade que comprometem a interação do usuário com o sistema, contribuindo para tornar tarefas comuns à rotina de pesquisadores uma experiência difícil e confusa. Tal condição é responsável por causar, por exemplo, um nível não esperado relacionado a atualização dos currículos na plataforma e, consequentemente, impactar nas métricas que utilizam o serviço para avaliar o rendimento de pesquisadores e instituições. Essa característica é clara ao se observar que, de acordo com Digiampietri et al. (2014), estima-se que o número de artigos publicados não informados na plataforma Lattes pode chegar a mais de $20 \%$.

No relacionado a essa questão, Brito, Quonam e Chalco (2016), relatam que o Lattes não apresenta um sistema de busca eficiente, pois nem todos os operadores de relação utilizados nos campos são reconhecidos pelo sistema. Outro problema é decorrente da confiabilidade das informações, uma vez que é uma base com livre inserção de dados, e por isso carece de padronização e validação de conteúdo (DIGIAMPIETRI et al., 2014).

No que tange à acessibilidade do sistema também foram encontradas inconsistências, como relatado por Barbosa, Santos e Reis (2010), com relação à utilização por deficientes visuais. Assim, ao analisarem a página inicial e algumas das principais funcionalidades (cadastro, atualização e busca de currículos), foram encontradas barreiras que tornaram seu uso pouco acessível para deficientes visuais parciais e inacessível para usuários com cegueira total.

Tendo em vista o cenário dessa problemática, o presente estudo buscou, a partir da ótica da usabilidade, compreender a maneira como a atual interface da plataforma Lattes se comporta nas tarefas mais comuns observadas nos típicos usuários do sistema. Nessa intenção, teve como objetivo principal avaliar a usabilidade da interface do sistema Lattes no que se relaciona aos níveis de sucesso, tempo e satisfação da tarefa. Essas métricas foram definidas porque estão respectivamente associadas aos critérios de eficácia, eficiência e satisfação, basilares para uma adequada experiência do usuário, conforme é discutido a seguir.

\section{Referencial Teórico}

Como se sabe, embora um estudo de usabilidade, dentre outras razões, frequentemente esteja associado a garantir que um sistema possua facilidade de uso suficiente para proporcionar qualidade interativa adequada aos processos de experiência com a interface, conforme Tullis e Albert (2013, p. 44), ao usuário interessa apenas dois fatores: o desempenho e a satisfação. Essa tese adquire sentido claro ao resgatarmos os
Realização:

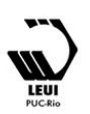




\section{$16^{\circ}$ \\ ERGODESIGN USIHC CINAHPA}

$16^{\circ}$ Ergodesign - Congresso Internacional de Ergonomia e Usabilidade de Interfaces Humano Tecnológica: Produto, Informações Ambientes Construídos e Transporte

$16^{\circ}$ USIHC - Congresso Internacional de Ergonomia e Usabilidade de Interfaces Humano Computador

CINAHPA | 2017 - Congresso Internacional de Ambientes Hipermídia para Aprendizagem. princípios basilares da usabilidade, como aqueles observados na ISO 9241-11, que define a usabilidade como "a medida na qual um produto pode ser usado por usuários específicos para alcançar objetivos específicos com eficácia, eficiência e satisfação em um contexto específico de uso (2002, p. 3)".

Nessa vertente, a eficácia é definida como a extensão e acurácia por meio da qual os usuários alcançam objetivos específicos (JORDAN, 1998; ISO 9241-11, 2002). Portanto, na condição de medida de desempenho, em uma tarefa (ou conjunto de tarefas), Jordan (1998) aponta que a eficácia pode ser verificada, por exemplo, a partir da capacidade de o usuário obter êxito; e também, por meio da comparação entre a eficácia estimada e a eficácia real observada, quando se deseja verificar o nível de eficácia atingido.

Por sua vez, a eficiência é caracterizada como "os recursos gastos em relação à acurácia e abrangência com as quais usuários atingem objetivos" (ISO 9241-11, 2002, p.3). Ou seja, se relaciona com a quantidade de esforço necessário para que o usuário consiga realizar dado objetivo. Assim, quanto menor for o esforço, maior será a eficiência. Também se tratando de métrica de desempenho, as medidas de eficiência são capazes de relacionar o nível de eficácia alcançada com o gasto de recursos. Dessa forma, pode-se avaliar o esforço mental ou físico expendido pelo usuário durante a atividade, o tempo gasto na realização da tarefa, o número de erros obtidos antes de se conseguir sucesso (TULIS \& ALBERT, p. 44) e os custos materiais ou financeiros requeridos (JORDAN, 1998).

Por último, a satisfação tem a ver com a ausência de desconforto no usuário durante a utilização de um produto, e a sua relevância como meio para atingir objetivos. Este último aspecto é o mais subjetivo dos elementos da Usabilidade, e o mais difícil para medir. Dessa forma, pode-se avaliar a satisfação geral com o uso do produto, a percepção do usuário com relação à interface $\mathrm{e}$ os componentes do sistema, as impressões do usuário por meio de comentários e análise de discurso, entre outros métodos. Como critério avaliativo, portanto, podem ser realizadas medidas com escalas de desconforto experimentado a partir, por exemplo, de questionários baseados em escala Likert (JORDAN, 1998).

A partir do que foi discutido, há uma tendência a se acreditar que os níveis de desempenho e de satisfação sejam diretamente relacionados. No entanto, conforme Tulis e Albert (2013) afirmam, é de se esperar que um usuário reporte altas taxas de satisfação em tarefas que demandam altas taxas cognitivas ou que classifique como ruim a experiência em um sistema que funcionou adequadamente. A interpretação a respeito de uma situação semelhante deve depender, portanto, de um julgamento acurado por parte do especialista que sempre precisa levar em consideração as questões específicas de cada projeto.

Finalmente, é importante destacar que não existe regra para a definição de métricas em um projeto engajado na avaliação de desempenho e satisfação do usuário. De fato, as métricas disponíveis são diversas e sua variabilidade visa atender necessidades específicas que podem se apresentar em diferentes ciclos de um projeto. Portanto, é pertinente que sua definição considere fatores frequentemente relacionados aos custos (tempo e recurso) disponíveis, ao tipo e número de usuários representantes do público-alvo e de avaliadores especialistas envolvidos, dentre outros que estão associados às características singulares da diversidade de questões que uma interface é capaz de revelar.

\section{Materiais e Métodos}

\subsection{Questionário Exploratório Preliminar}

Uma necessidade importante identificada no início do estudo foi a de extrair informações relevantes para se conhecer o perfil dos usuários e os problemas mais comuns enfrentados por eles nos processos de interação com a plataforma Lattes. Além disso, acreditou-se ser fundamental compreender, mesmo que de maneira genérica, questões relacionadas à frequência de uso e os tipos de tarefas mais utilizadas pelos usuários do sistema. 


\section{$16^{\circ}$ \\ ERGODESIGN USIHC CINAHPA}

Conforme ainda será apresentado mais adiante, essas informações foram basilares para fundamentar a escolha do método a ser utilizado, do perfil de participantes a ser recrutado, e das tarefas a serem empregadas no estudo. Nesse sentido, um questionário exploratório preliminar foi aplicado, através de um formulário online, em 20 indivíduos que afirmaram utilizar o sistema, e continha inquirições capazes de convergir para respostas de interesse a essa etapa.

A análise das respostas indicou o seguinte: a faixa etária dos participantes variou entre 22 e 55 anos; a grande maioria (85\%) é aluno ou docente de programa de pós-graduação nos níveis de especialização, mestrado, doutorado, ou estágio pós-doutoral; as tarefas mais frequentes compreenderam inserir ou atualizar dados cadastrais, atuação (profissional, de pesquisa, etc.), produção (artigos, publicações, etc.), e apresentação de trabalho em eventos; e as tarefas menos frequentes residiram em inserir ou atualizar informações sobre orientação e supervisão de pesquisa, e participação em banca julgadora, provavelmente pelo fato dessas serem mais específicas à atividade docente.

Os resultados demonstraram ainda que os problemas mais percebidos pelos usuários estão relacionados à carência de consistência na estrutura dos botões de navegação, falta de padrão quanto à informação indispensável para completar determinada tarefa, entradas similares para objetivos distintos, e feedback inexistente na ocorrência de erros.

\subsection{Método}

O objetivo da pesquisa foi avaliar a usabilidade da plataforma Lattes de modo a compreender a qualidade resultante da interação do usuário com esse sistema. Para essa finalidade, conforme é sintetizado no quadro 1, as métricas para avaliação de sucesso, tempo da tarefa, e satisfação do usuário, propostas por Tullis e Albert (2013), foram aplicadas na intenção de identificar, dentro dos limites definidos, os níveis de eficácia, eficiência e satisfação, respectivamente, tendo em vista que, conforme a ISO 9241-11, tratam-se de $16^{\circ}$ Ergodesign - Congresso Internacional de Ergonomia e Usabilidade de Interfaces Humano Tecnológica: Produto, Informações Ambientes Construídos e Transporte

$16^{\circ}$ USIHC - Congresso Internacional de Ergonomia e Usabilidade de Interfaces Humano Computador

CINAHPA | 2017 - Congresso Internacional de Ambientes Hipermídia para Aprendizagem. medidas influenciadoras da usabilidade de um sistema.

\begin{tabular}{|l|l|}
\hline Variável & Métrica \\
\hline Eficácia & Sucesso na realização da tarefa \\
\hline Eficiência & $\begin{array}{l}\text { Tempo para execução da tarefa (em } \\
\text { segundos) }\end{array}$ \\
\hline Satisfação & Dados autoreportados \\
\hline
\end{tabular}

Quadro 1 - Métricas de Usabilidade aplicadas no estudo. Fonte: desenvolvido pelos autores com base em Tullis e Albert (2013).

\subsubsection{Participantes}

A seleção dos participantes do experimento considerou o perfil de usuário identificado a partir dos resultados do questionário exploratório preliminar, anteriormente discutido. Definiu-se, portanto, o recrutamento de indivíduos com idade a partir de 22 anos e engajados, seja como professor ou aluno, em algum programa de pós-graduação.

Foram submetidos ao experimento 7 participantes pertencentes aos programas de pós-graduação da Universidade do Estado de Santa Catarina e da Universidade Federal de Santa Catarina. A amostra compreendia 4 participantes no nível de mestrado, 2 de doutorado e 1 de estágio pós-doutoral. Quanto ao nível de experiência do usuário relacionado à plataforma, 3 participantes relataram uma frequência de uso do sistema entre 1 a 6 vezes no último ano, e 4 afirmaram utilizar o sistema entre 7 e 12 vezes ao ano, e, portanto, foram categorizados como novatos e experientes, respectivamente.

No concernente ao número de participantes recrutados para o experimento, este considerou as recomendações de Tulis e Albert (2013), Preece et al. (2002), e Nielsen (2000) que respectivamente consideram o número de 6 a 8,5 a 12, e 5 participantes o suficiente para pesquisas dessa natureza, que visam compreender a fundo o comportamento de um grupo de indivíduos representativo do público-alvo durante a interação com um sistema.

\subsubsection{Coleta dos dados}

Os dados foram coletados no mês de maio de 2016
Realização:

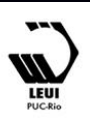




\section{$16^{\circ}$ \\ ERGODESIGN USIHC CINAHPA}

em dois ambientes diferentes, embora a preocupação em garantir as mesmas condições técnicas e laboratoriais tenham sido consideradas em ambos. Os experimentos foram realizados em salas que possuíam as seguintes características: computador equipado com sistema operacional Windows 7® e navegador Chrome; cronômetro digital; formulários em papel; mesa com cadeiras para o moderador e o participante; câmeras digitais para captura em fotografia e vídeo, com a finalidade de documentar as sessões e registrar verbalizações dos usuários.

Além disso, a pesquisa envolveu 4 pesquisadores bacharéis em Design e estudantes de pósgraduação stricto sensu, envolvidos no componente curricular "Métodos para avaliação de usabilidade" do Programa de Pós-graduação em Design da Universidade do Estado de Santa Catarina. A eles foram atribuídos papéis distintos divididos da seguinte forma: 1 moderador foi responsável por mediar as sessões, e 3 observadores compartilhavam funções como registro de tempo das tarefas e documentação das informações coletadas nos formulários.

As tarefas também foram selecionadas baseadas nos resultados identificados a partir do questionário exploratório preliminar, aqui já discutido. Portanto, foram definidas as tarefas 1) atualizar informação cadastral; 2) inserir linha de pesquisa; 3) inserir informação sobre apresentação e publicação de trabalho em evento; 4) inserir informação a respeito de publicação em periódico/revista; 5) imprimir a versão resumida do currículo. As instruções das cinco tarefas foram expostas impressas em papel, na forma de cenários de modo que os usuários pudessem compreender claramente o objetivo de cada uma delas, antes de executá-las. O quadro 2 apresenta o cenário de tarefas descrito da mesma forma que foi exposto aos participantes.

\footnotetext{
Tarefa 1: Imagine que você já preencheu todas as informações básicas do seu currículo Lattes. No entanto, você não tinha o documento de identidade em mãos, e não sabia o número. Agora você precisa atualizar esse dado. Execute essa tarefa.

Caminho correto: Dados Gerais > Identificação > Salvar
}

$16^{\circ}$ Ergodesign - Congresso Internacional de Ergonomia e Usabilidade de Interfaces Humano Tecnológica: Produto, Informações Ambientes Construídos e Transporte

$16^{\circ}$ USIHC - Congresso Internacional de Ergonomia e Usabilidade de Interfaces Humano Computador

CINAHPA | 2017 - Congresso Internacional de Ambientes Hipermídia para Aprendizagem.
Tarefa 2: Você precisa inserir a informação de que o projeto em que você está engajado faz parte da linha de pesquisa Interfaces e Interações Físicas. Execute essa tarefa.

Caminho correto: Atuação > Atuação Profissional > Selecionar a instituição > Atividades > Incluir novo item Tarefa 3: Você participou do IV IDEMI (International Conference on Design, Engineering, Management for Innovation) em 2015, apresentando o trabalho completo intitulado "Métodos para avaliação de distúrbios musculoesqueléticos em professores do ensino fundamental", que também foi publicado nos anais deste evento. Atualize essas informações no seu currículo. Caminhos corretos: 1) Produções > Trabalhos Publicados em Anais de Eventos Produções > Apresentação de Trabalho e Palestra; 2) Eventos > Participação em Eventos, congressos, exposições, feiras e olimpíadas > Forma de Participação > PARTICIPANTE; (caminho alternativo ao 2) Produções > Apresentação de trabalho e palestra; (caminho extra, não obrigatório) Eventos > Participação em Eventos, congressos, exposições, feiras e olimpíadas > Forma de Participação > OUVINTE

Tarefa 4: A submissão do seu artigo "Morfologia para setas em livros didáticos: Uma abordagem semiótica", foi aceita para publicação na revista digital Arcos Design (vol.18, no 2, 2015, ISSN 1984-5596, p. 120 - 131), como publicação em meio digital. Agora você quer inserir essas informações. Execute essa tarefa.

Caminho correto: Produções > Artigos aceitos para publicação

Tarefa 5: Você precisa imprimir a versão resumida do seu currículo para participar de um processo seletivo. Execute essa tarefa.

Caminhos corretos: 1) Menu Superior > Ícone Impressora; (caminho alternativo) Menu Lateral > Gerar página para impressão.

Quadro 2 - Descrição dos cenários de tarefa e dos caminhos no sistema adequados para sucesso da tarefa. Fonte: desenvolvido pelos autores.

No concernente ao questionário, este estruturou-se a partir das três métricas determinadas para medir os resultados de eficácia, eficiência e satisfação. A métrica relacionada à eficácia do sistema foi medida através do sucesso na execução da tarefa. Existiam caminhos específicos e apropriados para a conclusão de cada tarefa de forma que a conformidade com esses trajetos indicava se o usuário obteve êxito ou não em realizar da maneira correta o que lhe foi pedido. Considerou-se que alguns usuários poderiam, por qualquer razão, desistir da tarefa eventualmente, portanto lhes foi orientado que eles deveriam desistir no momento em que normalmente fariam se estivessem executando aquele processo em uma situação real. Os resultados eram então categorizados de maneira
Realização:

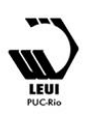




\section{$16^{\circ}$ ERGODESIGN USIHC CINAHPA}

$16^{\circ}$ Ergodesign - Congresso Internacional de Ergonomia e Usabilidade de Interfaces Humano Tecnológica: Produto, Informações Ambientes Construídos e Transporte

$16^{\circ}$ USIHC - Congresso Internacional de Ergonomia e Usabilidade de Interfaces Humano Computador

CINAHPA | 2017 - Congresso Internacional de Ambientes Hipermídia para Aprendizagem. binária, onde 0 representava não sucesso, e 1 representava sucesso.

A cada vez que um usuário desempenha uma tarefa, deve ser dado a ele uma pontuação de sucesso ou falha. Tipicamente, essas pontuações são representadas na forma de 1 (sucesso) e zero (falha). (A análise é mais fácil se você atribuir uma pontuação numérica do que um valor textual "sucesso" ou "falha"). Ao utilizar uma pontuação numérica você consegue calcular facilmente a porcentagem correta, assim como outras estatísticas que você precisa. Simplesmente calcule a média de 1 e 0 para determinar a percentagem correta (TULLIS \& ALBERT, 2013, p. 66, traduçãonossa).

Para obter resultados associados à eficiência do sistema, Tullis e Albert (2013, p. 74-75) propõem a métrica "tempo da tarefa" que consiste em medir, com o auxilio de um cronômetro, o tempo transcorrido em minutos e/ou segundos, entre o início e o final de cada tarefa.

Já os resultados relativos à satisfação do usuário foram obtidos através da medição de dados autoreportados que, segundo os autores, têm a capacidade de fornecer informações a nível emocional, a respeito da percepção dos usuários sobre a interação com o sistema (p. 123). Para essa finalidade, foram aplicados dois tipos de avaliação capazes de identificar a satisfação dos usuários relacionada a cada tarefa, e a satisfação relacionada a toda a experiência de utilização do sistema.

No que se refere ao primeiro tipo de avaliação da satisfação, utilizou-se uma escala Likert de 5 níveis (que variavam de forma crescente entre "insatisfeito" e "muito satisfeito") ao final de cada uma das 5 tarefas e, portanto, aqui é referido como "pós-tarefa". No segundo tipo de avaliação da satisfação, por outro lado, os usuários foram estimulados ao final da sessão a relatar suas percepções individuais a respeito da experiência completa de interação com o sistema. Nessa intenção, foi utilizado um questionário adaptado do SUS (System Usability Scale), de forma a comportar um número menor de perguntas, já que o objetivo de sua aplicação era complementar a avaliação de satisfação realizada ao final de cada tarefa. Esse questionário, chamado nessa pesquisa de "pós-estudo", continha 5 afirmações relacionadas à satisfação global do usuário que foram julgadas no concernente ao grau de concordância em uma escala de 1 a 5 , onde 1 representava "discordo totalmente" e 5, "concordo totalmente".

\begin{tabular}{|l|l|}
\hline Afirmação & Descrição \\
\hline 1 & $\begin{array}{l}\text { Eu me sinto confiante por ter usado o sistema } \\
\text { corretamente. }\end{array}$ \\
\hline 2 & $\begin{array}{l}\text { Acredito que eu precisaria de ajuda para saber como } \\
\text { usar o sistema. }\end{array}$ \\
\hline 3 & $\begin{array}{l}\text { Acredito que a maioria das pessoas aprenderiam } \\
\text { rapidamente como usar este sistema. }\end{array}$ \\
\hline 4 & De uma maneira geral, realizar as tarefas foi difícil. \\
\hline 5 & Eu achei o sistema fácil de usar. \\
\hline
\end{tabular}

Quadro 3 - Descrição das afirmações contidas no questionário de satisfação "pós-estudo".

Fonte: desenvolvido pelos autores, baseado em Albert e Tullis (2013).

\section{Resultados e Discussão}

Na tabela 1 estão apresentados os resultados extraídos do experimento relacionados às medidas de eficácia, eficiência e satisfação "pós-tarefa", e que são detalhadamente discutidos a seguir. Além disso, mais adiante, são expostos também os resultados e considerações a respeito do questionário de satisfação "pós-estudo" que foi aplicado ao final de cada sessão. Por fim, discutese também as questões associadas à influência do fator de experiência do usuário nos resultados obtidos.

Faz-se importante destacar que, devido ao pequeno número da amostra $(\mathrm{n}=7)$, característico a experimentos dessa natureza, os resultados obtidos permitem que as discussões que se seguem envolvam somente estatística descritiva.

\begin{tabular}{|c|c|c|c|}
\hline & Eficácia & Eficiência & Satisfação \\
\cline { 2 - 4 } & $\begin{array}{c}\text { Sucesso } \\
\text { da tarefa }\end{array}$ & Tempo (s) & $\begin{array}{c}\text { Satisfação } \\
\text { pós-tarefa }\end{array}$ \\
\hline TAREFA 1 & $\begin{array}{c}\text { Soma: } \\
\mathbf{7}\end{array}$ & $\begin{array}{c}\text { Média: } \\
\mathbf{2 9 , 4 3}\end{array}$ & - \\
\hline Participante 1 & 1 & 30 & 3 \\
\hline Participante 2 & 1 & 26 & 5 \\
\hline
\end{tabular}

Realização:

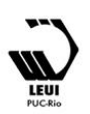




\section{$16^{\circ}$ \\ ERGODESIGN USIHC CINAHPA}

$16^{\circ}$ Ergodesign - Congresso Internacional de Ergonomia e Usabilidade de Interfaces Humano Tecnológica: Produto, Informações Ambientes Construídos e Transporte

$16^{\circ}$ USIHC - Congresso Internacional de Ergonomia e Usabilidade de Interfaces Humano Computador

CINAHPA | 2017 - Congresso Internacional de Ambientes Hipermídia para Aprendizagem.

\begin{tabular}{|c|c|c|c|}
\hline Participante 3 & 1 & 28 & 3 \\
\hline Participante 4 & 1 & 44 & 5 \\
\hline Participante 5 & 1 & 43 & 4 \\
\hline Participante 6 & 1 & 20 & 5 \\
\hline Participante 7 & 1 & 15 & 5 \\
\hline TAREFA 2 & $\begin{array}{c}\text { Soma: } \\
2\end{array}$ & $\begin{array}{c}\text { Média: } \\
182,5\end{array}$ & - \\
\hline Participante 1 & 0 & 465 & 2 \\
\hline Participante 2 & 0 & 131 & 1 \\
\hline Participante 3 & 0 & 273 & 1 \\
\hline Participante 4 & 0 & 341 & 1 \\
\hline Participante 5 & 1 & 206 & 1 \\
\hline Participante 6 & 1 & 159 & 1 \\
\hline Participante 7 & 0 & 99 & 2 \\
\hline TAREFA 3 & $\begin{array}{c}\text { Soma: } \\
0\end{array}$ & $\begin{array}{c}\text { Média: } \\
\text { 0 }\end{array}$ & - \\
\hline Participante 1 & 0 & 495 & 4 \\
\hline Participante 2 & 0 & 450 & 3 \\
\hline Participante 3 & 0 & 215 & 4 \\
\hline Participante 4 & 0 & 623 & 1 \\
\hline Participante 5 & 0 & 461 & 2 \\
\hline Participante 6 & 0 & 171 & 4 \\
\hline Participante 7 & 0 & 239 & 2 \\
\hline TAREFA 4 & $\begin{array}{c}\text { Soma: } \\
3\end{array}$ & $\begin{array}{c}\text { Média: } \\
257,66\end{array}$ & - \\
\hline Participante 1 & 0 & 204 & 4 \\
\hline Participante 2 & 1 & 170 & 4 \\
\hline Participante 3 & 0 & 75 & 5 \\
\hline Participante 4 & 1 & 501 & 2 \\
\hline Participante 5 & 0 & 394 & 3 \\
\hline Participante 6 & 1 & 102 & 4 \\
\hline Participante 7 & 0 & 144 & 3 \\
\hline TAREFA 5 & $\begin{array}{c}\text { Soma: } \\
7\end{array}$ & $\begin{array}{c}\text { Média: } \\
89,71\end{array}$ & - \\
\hline Participante 1 & 1 & 354 & 4 \\
\hline Participante 2 & 1 & 57 & 4 \\
\hline Participante 3 & 1 & 22 & 3 \\
\hline Participante 4 & 1 & 93 & 3 \\
\hline Participante 5 & 1 & 53 & 4 \\
\hline Participante 6 & 1 & 32 & 5 \\
\hline Participante 7 & 1 & 17 & 5 \\
\hline
\end{tabular}

Tabela 1 - Resultados de sucesso, tempo e satisfação reportados por cada usuário para cada tarefa.

Fonte: desenvolvido pelos autores.

\subsection{Eficácia}

Na tabela 1, onde são apresentados os resultados do sucesso da tarefa é possível observar que, enquanto a totalidade dos usuários obteve êxito ao realizar as tarefas 1 e 5 , apenas 2 e 3 usuários foram capazes de concluir as tarefas 2 e 4 , respectivamente. $\mathrm{Na}$ tarefa 2 , o problema latente estava associado à inconsistência do menu superior do sistema, que agrupa o link "Linha de pesquisa" sob a dimensão "Atuação", o que poderia ser intuitivo, não fosse o fato de que, ao selecionar essa opção, uma janela pop-up informa que o usuário precisa percorrer outro caminho. Muito embora se acredite que essa mensagem pudesse resolver o problema, ela não é apresentada de maneira que o usuário consiga visualizá-la imediatamente, condição que contribuiu para confundir mesmo aqueles poucos usuários capazes de concluir a tarefa, e para motivar desistência no restante. $\mathrm{Na}$ tarefa 4 , onde os usuários precisavam informar o aceite da submissão de um artigo, alguns participantes inseriram a informação em local destinado a artigos já publicados, e outros, em destino completamente diferente do que era intencionado, como "Texto em jornal ou revista". Além disso, essa opção estava disponível tanto em "Produções", quanto em "Educação e Popularização de C\&T", uma distinção desconhecida pela maioria dos usuários.

No entanto, a tarefa 3 foi a que obteve os resultados de eficácia mais críticos, tendo em vista que nenhum dos participantes conseguiu realizar os passos da maneira correta ou completa. O cenário da tarefa pedia que fossem inseridos dados relacionados à apresentação de um trabalho em evento, e a publicação deste nos anais. Enquanto alguns usuários informaram apenas os dados referentes à publicação no evento, aqueles que tentaram informar a apresentação do trabalho encontraram destinos alternativos como "Participação em eventos, congressos, exposições, feiras e olimpíadas" e "Apresentação de trabalhos e palestras". Outra questão importante relacionada a essa tarefa se deu em função de um usuário desconhecer a finalidade da ferramenta DOI (Digital Document Identifier), forçando-o a procurar por essa informação em um site externo, embora sem êxito. É certo que a complexidade da tarefa pode tornar sua execução difícil, no entanto, percebe-se que a similaridade dos termos empregados para funções distintas, a falta de organização adequada na estruturação do sistema, e o emprego de termos dos quais os usuários não estão familiarizados, são condições que tornaram os resultados de eficácia nessa tarefa inferiores aos demais. 


\section{$16^{\circ}$ \\ ERGODESIGN USIHC CINAHPA}

$16^{\circ}$ Ergodesign - Congresso Internacional de Ergonomia e Usabilidade de Interfaces Humano Tecnológica: Produto, Informações Ambientes Construídos e Transporte

$16^{\circ}$ USIHC - Congresso Internacional de Ergonomia e Usabilidade de Interfaces Humano Computador

CINAHPA | 2017 - Congresso Internacional de Ambientes Hipermídia para Aprendizagem.

\subsection{Eficiência}

A noção de eficiência em nossos estudos esteve associada ao tempo de execução das tarefas. $\mathrm{Na}$ tabela 1 também é possível observar os resultados de cada participante representados em segundos para cada tarefa. É importante salientar que a média do tempo foi calculada considerando apenas os resultados dos usuários que obtiveram êxito nas tarefas, uma vez que, conforme Tullis e Albert (2013, p. 81), o tempo relacionado a uma tarefa incompleta ou não concluída pouco interessa, visto que o insucesso por si só sugere omissão de usabilidade e a necessidade urgente de intervenção. Uma outra questão levantada pelos autores implica que a representação dos valores através da mediana ou média geométrica pode ser mais adequada por serem menos influenciadas por pontos discrepantes ou grande variação de tempo. Todavia, eles também destacam que, na prática, os padrões que interessam, como por exemplo a comparação entre tarefas, geralmente permanecem os mesmos (TULLIS e ALBERT, 2013, p. 79). Diante dessas considerações, definiu-se como relevante representar os resultados por meio da média.

Na tarefa 1, que foi concluída por todos os participantes, apesar de o tempo médio ter sido 29,43 segundos, um dos participantes conseguiu concluí-la em 15 segundos, um resultado quase três vezes inferior aos 43 e 44 segundos conseguidos pelos usuários que levaram mais tempo. Essa característica sugere que a interface destinada à inserção/atualização de dados cadastrais possui uma boa capacidade interativa, no entanto, sugerese considerar alguns ajustes na intenção de tornar os resultados mais próximos do menor observado.

Os resultados da tarefa 2, muito embora tenham apresentado um baixo índice de eficácia, não variaram significativamente entre os usuários que conseguiram concluí-la. No entanto, por se tratar de uma tarefa simples, resultados como 169 e 206 segundos foram considerados como longos pelos usuários. Já a análise dos resultados de tempo provenientes da tarefa 3 apontam um problema ainda mais crítico, uma vez que o usuário pode perder um tempo de até 623 segundos em um processo que o guiará a caminhos alheios à intenção, culminando em desistências ou ações incorretas.

A média de tempo obtida na tarefa 4 pelos usuários bem-sucedidos foi 257,66 segundos. Percebe-se, contudo, que a variação entre eles foi gigantesca, sugerindo inconsistências na interface que podem levar alguns usuários a despender mais tempo em relação a outros. Considerando os diferentes caminhos que os participantes tomaram para chegar ao destino, essa condição parece estar associada com termos, ferramentas ou estruturas presentes na interface que podem não ser compreendidos por alguns indivíduos.

Por outro lado, a tarefa 5 que envolvia a impressão do currículo foi completada por todos os participantes, e obteve 89,71 segundos como média de tempo. Enquanto seis, dentre os sete usuários, levaram entre 17 e 93 segundos para finalizá-la, um participante demorou 354 segundos. Esse afirmou que, como o sistema nunca organizava as informações do currículo em uma formatação adequada, ele sentia a necessidade de exportar o arquivo para determinado formato e realizar as formatações a seu gosto. Apesar de parecer um caso isolado, seria relevante compreender mais a fundo as dificuldades enfrentadas por este usuário, de modo a extrair informações que pudessem interessar também a um número maior de indivíduos. Quanto aos caminhos utilizados para impressão do currículo, não houve um consenso entre os dois que estão disponíveis na interface.

\subsection{Satisfação}

Em nosso estudo, a medida de satisfação foi associada às métricas de satisfação do usuário tanto no relacionado a cada tarefa, através de uma escala Likert, quanto à totalidade da experiência, por meio de um questionário de satisfação "pósestudo". Nesse primeiro momento, trataremos de discutir os resultados de satisfação associados a cada tarefa.

O gráfico 1 ilustra as pontuações reportadas por cada participante (P1, P2, P3...) após completar cada uma das 5 tarefas, que também estão representadas na tabela 1. É importante ressaltar 


\section{$16^{\circ}$ \\ ERGODESIGN USIHC CINAHPA}

$16^{\circ}$ Ergodesign - Congresso Internacional de Ergonomia e Usabilidade de Interfaces Humano Tecnológica: Produto, Informações Ambientes Construídos e Transporte

$16^{\circ}$ USIHC - Congresso Internacional de Ergonomia e Usabilidade de Interfaces Humano Computador

CINAHPA | 2017 - Congresso Internacional de Ambientes Hipermídia para Aprendizagem. aqui que as pontuações oferecidas pelos participantes em resposta à pergunta "como você se sente em relação a sua performance nessa tarefa?", representavam respectivamente, em uma escala de 1 a 5 , "insatisfeito", "pouco satisfeito", "neutro", "satisfeito" e "totalmente satisfeito". Nessa perspectiva, é possível observar que as tarefas 1 e 5 - que foram concluídas por toda a amostra de participantes - tiveram uma tendência a receber as maiores pontuações de satisfação, superiores a 4 .

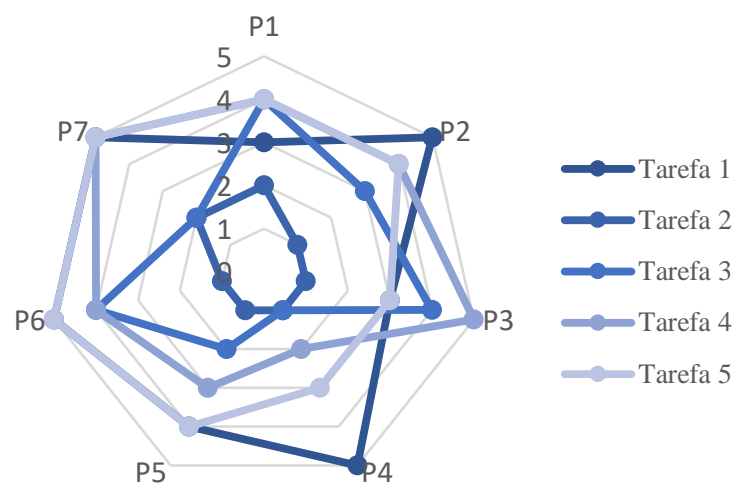

Gráfico 1 - Resultados das classificações de satisfação reportados por cada participante após cada tarefa.

Fonte: desenvolvido pelos autores.

As tarefas 3 e 4, por outro lado, receberam resultados mais variados, apesar de esta última ter se saído melhor, com pontuações mais próximas de 4. É curioso observar, no entanto, que nenhum dos participantes conseguiu concluir a tarefa $3 \mathrm{e}$, mesmo assim, esta recebeu a pontuação 4 por 3 dos participantes. Tal condição pode ter se manifestado diante do fato de que alguns participantes acreditaram ter concluído a tarefa com eficácia, quando, na verdade, tinham falhado. Essa questão reforça a característica crítica dos resultados apresentados por essa tarefa, levando a crer que $o$ sistema é problemático ao ponto de causar nos usuários sensações equivocadas.

Por outro lado, conforme esperado na tarefa $2 \mathrm{em}$ que o sistema informa caminhos falsos (conforme já foi discutido), as pontuações de satisfação ficaram próximas aos níveis mais baixos, uma vez que, mesmo nas ocasiões de sucesso, os usuários consideraram os caminhos demasiadamente confusos e demorados.

Consequentemente, ao se associar a satisfação "pós-tarefa" com os resultados de eficácia e eficiência, não é possível observar padrões bem definidos. Apesar de, na maioria das tarefas, os altos níveis de satisfação parecerem depender de boas eficácia e eficiência; a tarefa 3 , em que nenhum dos participantes foi capaz de completá-la, não apresentou uma associação direta entre eficácia e satisfação. Esse resultado também é nítido na tarefa 4 , conforme já discutimos aqui.

Por fim, a inquirição realizada ao final das sessões relacionada à satisfação global, por meio do questionário "pós-estudo", consolida os resultados identificados nas classificações de satisfação "póstarefa", anteriormente discutidas. Conforme já foi apresentado, esse questionário continha cinco afirmações que deveriam ser julgadas pelos participantes em relação ao nível de concordância, utilizando uma escala que variava entre a dimensão mais baixa ( $1=$ discordo totalmente) e a dimensão mais alta $(5=$ concordo totalmente).

Como é possível observar no gráfico 2, na afirmação 5, relacionada à confiança em usar o sistema corretamente, houve uma tendência dos participantes apontarem classificação neutra. Por outro lado, as pontuações observadas para as afirmações 1 e 2 sugerem que os usuários tendem a caracterizar como difícil tanto o uso do sistema quanto a realização das tarefas. Esse comportamento parece estar de acordo com as respostas observadas na tarefa 3 , onde a maioria dos participantes estavam céticos em acreditar que novos usuários do sistema aprenderiam rapidamente a utilizá-lo; e na tarefa 4, que aponta para uma tendência dos participantes a acreditarem que dependeriam de ajuda para saber a forma correta de utilizar o sistema.

Por conseguinte, acredita-se, a partir dos resultados oriundos do questionário "pós-estudo", que a plataforma Lattes torna frustrante a experiência do usuário principalmente no aspecto de facilidade de
Realização:

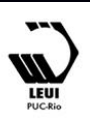




\section{$16^{\circ}$ \\ ERGODESIGN USIHC CINAHPA}

uso que se caracteriza como um dos mais importantes para usabilidade de um sistema, mas não somente. As percepções dos participantes relacionadas à necessidade de auxílio para utilizar o sistema e à carência de facilidade de aprendizagem podem ter sido derivadas da baixa taxa de sucesso observada nas tarefas e, em alguns casos, dos demasiados períodos de tempo que os usuários foram forçados a dispor, condições que reforçam os indícios apresentados pelas outras métricas.

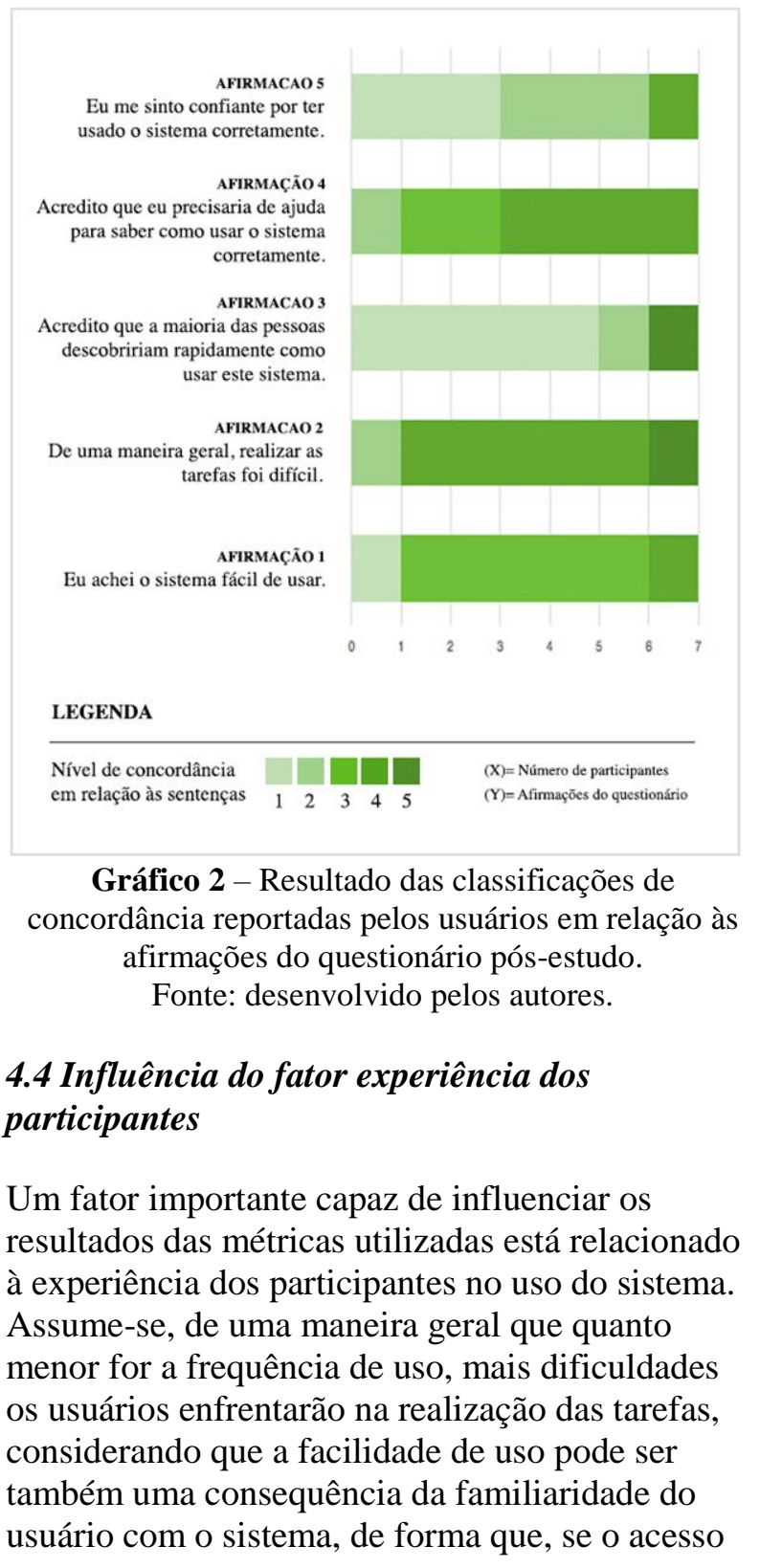

$16^{\circ}$ Ergodesign - Congresso Internacional de Ergonomia e Usabilidade de Interfaces Humano Tecnológica: Produto, Informações Ambientes Construídos e Transporte

$16^{\circ}$ USIHC - Congresso Internacional de Ergonomia e Usabilidade de Interfaces Humano Computador

CINAHPA | 2017 - Congresso Internacional de Ambientes Hipermídia para Aprendizagem. ao sistema é demasiadamente espaçado, a memorização dos caminhos adequados para executar determinadas tarefas pode ser comprometida.

Em nosso estudo, julgou-se relevante considerar os participantes que reportaram frequência de uso inferior a 6 vezes por ano como novatos, e aqueles que relataram uma frequência superior a esse valor, como experientes. Dessa forma, os participantes 3, 4 e 7 foram categorizados como novatos e o restante como experientes.

Ao observarmos os resultados de maneira separada entre os usuários novatos e experientes, é possível observar que o fator experiência não exerce forte influência nas medidas de sucesso, tempo e satisfação, muito embora esta primeira parece receber mais influências do que as outras. Nesse sentido, apesar de os participantes novatos terem apresentado uma frequência maior de insucesso nas tarefas de resultados mais críticos (tarefas 2, 3 e 4), a não conclusão de tarefas também ocorreu entre os participantes experientes. Com relação ao tempo, tanto usuários novatos quanto experientes apresentaram resultados altos em determinadas tarefas, um padrão que também pode ser observado no que se relaciona às baixas classificações de satisfação. Essas características sugerem que o sistema possui questões de usabilidade críticas a ponto de prejudicar a experiência do usuário até mesmo naqueles usuários que costumam utilizá-lo com maior frequência.

\section{Considerações Finais}

A plataforma Lattes é um sistema unificado que integra as bases de dados de currículos acadêmicos no Brasil, utilizada para gerenciar e registrar informações relacionadas à atuação acadêmica, profissional e de pesquisa. Por ser o sistema oficial adotado pelo CNPq, esse sistema possui um número significativo de usuários, contudo, sua interface parece carecer de um projeto adequado aos princípios de usabilidade responsáveis por garantir uma experiência de uso apropriada. Confrontado com essa problemática, o presente estudo objetivou avaliar a usabilidade da plataforma Lattes a partir de experimentos com 7 


\section{$16^{\circ}$ \\ ERGODESIGN USIHC CINAHPA}

participantes representativos dos usuários finais, explorando os aspectos de eficácia, eficiência e satisfação, de modo a identificar os principais problemas que contribuem para dificultar a experiência de uso nesse sistema. Nesse sentido, em um primeiro momento, o perfil dos usuários finais do sistema, assim como as principais tarefas utilizadas por estes foram identificados através de um questionário preliminar que apontou os direcionamentos importantes para essa pesquisa. Assim, as métricas de sucesso, tempo e satisfação da tarefa, juntamente com um questionário de satisfação global foram aplicados.

Dentre as descobertas, a tarefa 1 que envolvia a atualização de dados cadastrais foi a que apresentou melhores resultados, oferecendo sucesso a todos os participantes e os menores períodos de tempo para realização, o que proporcionou também os mais altos graus de satisfação.

Na tarefa 2, destinada à informação da linha de pesquisa, apenas 2 participantes conseguiram êxito em um período de tempo não adequado para uma atividade simples, acarretando baixos níveis de satisfação. Apesar de o sistema disponibilizar um caminho intuitivo no menu principal para executar essa tarefa, uma janela pop-up se abria informando que o usuário precisava tomar outro caminho, muito embora a mensagem não tenha sido visível para todos eles. Esse problema não apenas obriga o usuário a efetuar mais cliques, como também torna a tarefa um processo demorado e demanda demasiada carga cognitiva. Uma solução possível seria permitir que o usuário inclua nessa primeira janela a informação requerida.

A questão mais latente do sistema foi identificada a partir da tarefa 3 , onde o usuário precisava incluir informações relacionadas tanto à apresentação de um trabalho em evento, quanto à publicação nos anais deste. Nenhum dos usuários obteve sucesso em concluir toda a tarefa por diferentes razões.

Enquanto alguns foram capazes de informar apenas a publicação nos anais, os outros que tentaram incluir a apresentação do trabalho foram confundidos por diferentes destinos e, quando decidiram por um, enfrentaram outros problemas como termos técnicos dos quais os usuários não estavam familiarizados e campos que não conseguiam completar. Muito embora algumas das notas de satisfação tenham sido baixas conforme é esperado em uma tarefa carente de eficácia, alguns usuários relataram notas próximas dos níveis mais altos, condição que pode se justificar no fato de terem acreditado no sucesso da tarefa. Como, geralmente, a publicação de um trabalho está associada com a apresentação e participação como ouvinte no evento, o sistema poderia simplificar esse processo ao permitir a entrada única de todas as informações relacionadas ao mesmo evento em uma mesma tela, de forma que o usuário pudesse marcar as caixas destinadas ao tipo de participação desempenhada no evento (ex.: ouvinte, apresentação, publicação). Seria ideal também que a marcação dessas caixas também permitisse os campos obrigatórios para preenchimento suficiente do formulário, reduzindo a carga cognitiva e o tempo de execução, o que consequentemente aumentaria as taxas de sucesso e satisfação.

Apenas três dos usuários conseguiram concluir a tarefa 4, cujo objetivo era informar que um artigo foi aceito para publicação, em períodos de tempo que variaram significativamente. Com relação à satisfação, essa tarefa não apresentou padrões associados diretamente com a eficácia e eficiência do sistema. $\mathrm{O}$ ponto mais importante aqui reside no fato de alguns usuários terem se enganado em caminhos adversos à intenção, juntamente com a confusão provocada por termos similares, mas de funções diferentes. Uma solução possível de ser colocada em prática é similar à sugerida para a tarefa anterior, mas em um processo ainda mais interativo. Em uma mesma tela o usuário poderia inserir as informações que possui no momento em que o artigo foi aceito, marcando a caixa "artigo aceito para publicação", e informando uma data prevista para publicação de forma que, naquela data, o sistema exibisse uma notificação questionando se o usuário já possui as informações de publicação (como DOI, ISSN, número de páginas, etc.). Dessa forma, o usuário habilitaria a caixa "artigo publicado" e o sistema habilitaria os campos para inserir as novas informações. Nessa mesma tela ainda poderia ser exibido uma caixa para selecionar se o artigo se refere a "educação e
Realização:

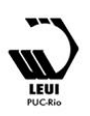




\section{$16^{\circ}$ \\ ERGODESIGN USIHC CINAHPA}

$16^{\circ}$ Ergodesign - Congresso Internacional de Ergonomia e Usabilidade de Interfaces Humano Tecnológica: Produto, Informações Ambientes Construídos e Transporte

$16^{\circ}$ USIHC - Congresso Internacional de Ergonomia e Usabilidade de Interfaces Humano Computador

CINAHPA | 2017 - Congresso Internacional de Ambientes Hipermídia para Aprendizagem. popularização de C\&T”, o que evitaria a necessidade de um menu apenas para essa categoria. Tal intervenção de design garantiria um processo mais simples capaz de reunir informações similares na mesma tela, evitando confusões relacionadas aos termos.

De maneira similar à primeira tarefa, a tarefa 5 destinada a impressão do currículo resumido foi capaz de proporcionar êxito a todos os participantes, em períodos de tempo relativamente aceitáveis e com níveis de satisfação próximos aos mais altos, apesar de um participante ter levado mais tempo ao exportar o arquivo para corrigir manualmente erros de diagramação alegados. Provavelmente por conta da taxa de sucesso, os níveis de satisfação não foram críticos. É importante, nesse sentido, observar a queixa relacionada aos problemas de diagramação na impressão do currículo de forma a tornar essa tarefa ainda mais satisfatória.

Os resultados provenientes do questionário de satisfação "pós-estudo" apontaram que os usuários possuem dúvidas quanto a facilidade de uso do sistema, além de alegarem a necessidade de auxilio para executar as tarefas e sentirem que novos usuários enfrentariam dificuldades para aprender como utilizá-lo. Por fim, observou-se ainda que o fator experiência do usuário não exerceu influências significativas nos resultados e, diante das questões criticas de usabilidade identificadas na plataforma, acreditamos que o sistema é problemático ao ponto de prejudicar a experiência do usuário até mesmo nos mais experientes.

É importante destacar que os resultados apresentados nesse estudo, assim como as análises executadas pelos autores estão estritamente associadas aos limites empregados. Portanto, levando em consideração o número reduzido de participantes envolvidos nesse tipo de estudo, sugere-se que, em trabalhos futuros, uma outra metodologia capaz de compreender uma amostra maior seja utilizada de forma a abranger outras questões de usabilidade possivelmente inviáveis de terem sido contempladas aqui. Acredita-se também que um estudo igualmente valioso possa compreender uma intervenção no design da plataforma Lattes a partir dos resultados produzidos pela presente pesquisa, de forma que a aplicação das mesmas métricas apresentaria resultados passíveis de serem comparados com os nossos.

\section{BIBLIOGRAFIA}

AMORIM, Cristiane. Organização do Currículo - Plataforma Lattes. In: Pesqui.Odontol.Bras, 2003.

BARBOSA, Glívia; SANTOS, Natália; REIS, Soraia. Relatório de Avaliação de Acessibilidade da Plataforma Lattes do CNPq sob a

Perspectiva de Deficientes Visuais. In: Anais Estendidos do IHC 2010 - IX Simpósio sobre Fatores Humanos em Sistemas Computacionais. Belo Horizonte - MG, Brasil.

BRITO, Aline; QUONIAM, Luc; MENACHALCO, Jesús. Exploração da Plataforma Lattes por assunto: proposta de metodologia. In: Trans (In)formação. Campinas 28 (1): p.77-86. 2016.

CONSELHO NACIONAL DE

DESENVOLVIMENTO CIENTÍFICO E TECNOLÓGICO (CNPq). Dados e estatísticas da

Plataforma Lattes. 2016. Disponível em: <http://www.cnpq.br/web/portal-lattes/dados-eestatisticas $>$. Acesso em 02-02-2017.

DIGIAMPIETRI, Luciano et.al. Análise macro das últimas atualizações do Currículo Lattes. In: Revista da Faculdade de Biblioteconomia e Comunicação da UFRGS. v.20, n³, 2014.

ISO 9241-11. Requisitos Ergonômicos para Trabalhos de Escritórios com Computadores. Parte 11 - Orientações sobre Usabilidade. ABNT Associação Brasileira de Normas Técnicas, 2002.

JORDAN, Patrick. An Introduction to

Usability.Londres: Taylor \& Francis, 1998.

NIELSEN, Jakob. Why you only need to test 5 users.2000. Disponível em:

$<$ https://www.nngroup.com/articles/why-you-onlyneed-to-test-with-5-users/>. Acesso em 01-02- 


\section{$16^{\circ}$ \\ ERGODESIGN USIHC CINAHPA}

$16^{\circ}$ Ergodesign - Congresso Internacional de Ergonomia e Usabilidade de Interfaces Humano Tecnológica: Produto, Informações Ambientes Construídos e Transporte

$16^{\circ}$ USIHC - Congresso Internacional de Ergonomia e Usabilidade de Interfaces Humano Computador

CINAHPA | 2017 - Congresso Internacional de Ambientes Hipermídia para Aprendizagem.

2017.

TULLIS, T.; ALBERT, B. Measuring the user experience: collecting, analyzing, and presenting usabiity metrics. Elsevier, 2013.

\section{Agradecimentos}

Agradecemos à Capes que foi responsável pelo financiamento desta pesquisa, ao $\mathrm{CNPq}$, aos professores e coordenação do Programa de Pósgraduação em Design da UDESC, e aos professores e bolsistas do Pós Design UFSC. 